\title{
Macroeconomic Turbulence: Corporate Performance, Transparency and Economic Growth
}

\author{
Lars Oxelheim ${ }^{1}$
}

\begin{abstract}
Transparency and economic growth have become buzzwords in the economic and political debate in recent years. On the one hand, a lack of transparency is used as an ex post explanation for corporate scandals such as Enron, WorldCom and Parmalat and bank scandals such as Société Général with assumed effects on economic growth. On the other hand, transparency is advocated as an ex ante driver of improved economic growth, as in the Lisbon Agenda with its use of benchmarking (and the Open Co-ordination Method). Few research reports have tried to link transparency to economic growth. Transparency is a multidimensional and situationrelated word, with information asymmetry as a kind of lowest common denominator. This chapter addresses optimal transparency concerning macroeconomic influences on the individual firm. It discusses to what extent the implementation as of January 2005 of the International Financial Reporting Standards (IFRS) for listed consolidated European firms will contribute to a reduced information asymmetry, lower agency costs, lower cost of capital, increased investment and to higher economic growth at the macro level.
\end{abstract}

JEL: G15, G32, M21, M38, M41.

Key concepts: Macroeconomic fluctuations, corporate performance, transparency, economic growth, information asymmetry, IFRS.

1 Lars Oxelheim holds the South Sweden Industry Chair in International Business and Finance at the Lund Institute of Economic Research, Lund University. He is affiliated with the Research Institute of Industrial Economics, Stockholm, and with the Fudan University, Shanghai. The Paper was presented at the symposium in honour of Professor Gudmundur Magnusson, University of Iceland, Reykjavik, November 2007. The choice of topic is explained by Professor Magnusson's interest in corporate risk issues. He has, together with Professor Oxelheim, co-authored an article on the relationship between macroeconomic factors and corporate creditworthiness. 


\section{Introduction}

Although the terms transparency and economic growth are likely to appear frequently today in any discussion of political economy, research on the link between these two phenomena is limited to only a few published studies. Interest in economic growth has a long history, while the concept of transparency, in both public debate and research, is of relatively recent origin. As an example of the increasing scientific interest in the concept of transparency it could be pointed out that only 32 instances of the word transparency appeared in working papers published by the prestigious National Bureau of Economic Research during the period 1974-2005, the first of them not until 1993 and most of the instances in working papers published after 2000 (Forssbaeck \& Oxelheim, 2006). The frequency of usage appears to have increased in parallel with the development of information technology.

While the meaning of the word can vary from one situation to another, the common denominator in a lack of transparency is some form of information asymmetry. In the political context, it often means a difficulty in understanding current policy and uncertainty as to what the next step may be. The price for this lack of transparency appears in the form of a political risk premium, which can be translated quantitatively into unrealised growth (Oxelheim, 1996). The Lisbon Agenda - which prescribes how Europe is to be transformed into the most competitive and dynamic knowledge-based economy in the world - makes transparency a prerequisite for the application of the open method of co-ordination (OMC). In this chain of causation, it is easy to understand how increased transparency in policy making can result in reduced political risk, a lower risk premium in the cost of capital, higher investment and increased economic growth for the society as a whole. Here political risk is viewed as a macroeconomic phenomenon, which affects all parties although vulnerability may vary from one enterprise to the next.

There is, however, political risk exposure where not only vulnerability but also the risk itself can be enterprise-specific. This exposure occurs where politicians intervene with programmes tailored to the specific needs of enterprises, aimed for instance at attracting a specific enterprise to the country. Here the politicians' conduct generates uncertainty among competitors as to who is next in line to receive such treatment, which can radically change the competitive circumstances for the specific company (Oxelheim \& Ghauri, 2004).

In the business world, the lack of transparency is often visible in communications between those parties with special insight into a company's dealings (insiders) and others who have interests at stake in this company but lack insight (outsiders). The theory on the supply and demand for company-specific information, however, is weak (Bushman et al, 2004), and this applies if possible to an even greater degree when the supply and demand is linked to economic growth (Oxelheim, 2006). Basically, however, access to information is regarded as a central determinant in effective decisions on resource allocation and growth in an economy (Levine, 1997).

The cost of a lack of corporate transparency can be expected to appear in the form of agency cost and risk premium which results in a lower valuation of the company. Improved transparency in individual companies can therefore be expected to appear 
in the form of higher valuation, lower cost of capital and increased investment. Individual companies can use various methods to improve their transparency relative to their competitors and by so doing lower their cost of capital (Oxelheim, 2001, Reese \& Weisbach, 2002, Oxelheim \& Randöy, 2003). Small and medium-size enterprises (SMEs) often see more limited possibilities of advancing in this manner. At the national and regional level there are therefore good reasons for politicians to be interested in questions of how to reduce information asymmetry. They can work to improve transparency through the national or regional regulatory framework. Other things being equal, this will lead to higher growth. The introduction of International Financial Reporting Standards (IFRS) within the EU in 2005 was such an attempt at the regional level. As a step in the direction towards improved transparency, all listed consolidated larger companies (with very few exceptions) within the EU had to change their accounting practices to conform to IFRS as of 2005.

This chapter discusses to what extent IFRS in their current formulation can make a contribution to improved transparency, a lower cost due to information asymmetry, improved cost of capital, more investment and, in turn, higher economic growth in individual European countries or in Europe as a whole. Since there is currently no more than scarcely two years of information flow under IFRS, an empirical analysis will necessarily be secondary to the normative message. The chapter focuses on information concerning a specific phenomenon: how much of the company's performance is intrinsic and not just a result of macroeconomic fluctuations during the accounting period. Apart from the many different approaches of accounting theory, this chapter deals with the communication of information of significance for understanding the company's intrinsic competitiveness and future income generating possibilities.

\section{Optimal Corporate Transparency}

A lack of transparency is often cited as the prime explanation for how many large corporate and banking scandals in recent years - such as Enron, Tyco, WorldCom, Parmalat and Société Général - managed to reach almost incomprehensible proportions. In the ensuing debate the implicit assumption has been that the more information disclosed by the company the better. Just how reasonable such an assumption is, can, however, be seriously questioned (Morris \& Shin, 2002). Somewhere along the way, before the receiver is drowned in information and left utterly confused, there is likely a point which could be described as optimal transparency (Oxelheim, 2006). In this case "optimal" refers to the receiver of information, i.e. the outside interest which we can represent here as the shareholder without insight.

"Optimal" can, however, also apply to the company's supply of information and the fact that there is an upper information limit which should not be exceeded in order to avoid revealing to competitors sensitive details connected to the company's profit opportunities (Verrecchia, 2001). "Optimal" as seen from these two perspectives may converge in a longer-term perspective. The external shareholder may have to revise his/her view of the demand for information bearing in mind the damage which the "last" bits of information on the margin can cause the company. 
As a third perspective on "optimal" transparency, management may have the degree of transparency reflect its own interests. The theory of corporate finance and corporate governance is very cynical in this respect, finding numerous reasons for having management's optimal information disclosure deviate from both of the other above-mentioned perspectives (Jensen \& Murphy, 1990, Oxelheim \& Wihlborg, 2003, Oxelheim \& Randöy, 2005). Corporate scandals throughout the world have also resulted in recommendations and legislation, for example, such as the SarbanesOxley Act in the US and the EU Transparency Directive. In the latter instance, IFRS is expected to contribute to increased transparency

\section{Transparency and Corporate Competitiveness}

Uncertainty concerning the company's "true" performance or outcome can have many sources and exist among many categories of interested parties. As mentioned in the introduction, we focus here on the uncertainty arising from changes in a company's macroeconomic environment. Exchange rates, interest rates or price developments which are positive (negative) for the company may have inflated (lowered) its performance in a way that gives false signals as to the company's competitiveness in case these effects on the performance are not clarified or filtered out.

With regard to the various categories of interested parties, we distinguish those who have insight into company operations and information to report - such as the CEO, senior management, the board of directors with its chairman, from those who lack insight and require information - such as analysts, pension fund managers or equity investors. To simplify the presentation, in the following discussion the management of the company will be understood to represent the supply of and the shareholders (without insight) the demand for company-specific information.

Uncertainty as to the impact of macroeconomic fluctuations on corporate performance and competitiveness will here be emphasized as a communication problem between the management and the shareholders of a firm. In the worst case, the uncertainty could even apply to the management and the board, if they have failed to devote sufficient attention and effort to analysing the distorting impact of macroeconomic factors on the image of the company's actual performance and competitiveness. In such case - which unfortunately appears to be not uncommon there is not so much to report to shareholders. At best, a warning can be issued that the effects may occur. At worst, reports can (unintentionally) mislead.

\section{Macroeconomic Effects on Corporate Performance}

In today's economically and financially integrated world, it is difficult to find an example in the real world of a company not impacted by global economic developments. Hence, there is no excuse for any company not to have a suitable analysis of the interplay between the company and its macroeconomic environment. Financial theory is, as mentioned, cynical and points to many possibilities for the management to use effects of macroeconomic fluctuations to its own advantage. Regardless of the communication strategy, it is equivalent to a breach of duty if a chairman fails to ask management for a detailed analysis of the performance with 
macroeconomic fluctuations being filtered out. In other words, every company should have comprehensive data to report.

\subsection{Transparency as Expressed by Accounting Standards}

Assume that management has made a suitable analysis. How much of its outcome should the company then pass on to shareholders through press releases and documentation accompanying its accounts? What information is the "informed" shareholder seeking? What should be regarded as "optimal transparency" in the information disclosed by the company to shareholders? IFRS can be regarded as representing a proxy for the demand side of this exchange of information. As regards the demand for information on the impact of macroeconomic factors, a break with tradition can be discerned in International Accounting Standard 1 (IAS 1, 1997 Rev.). Paragraph 8 of this standard encourages the company to present an analysis of the impact of the most important factors of its external operating environment on its performance. The company is thereby advised to pin-point these factors, how large the effects of any changes to them would be on performance, plus what strategy the company has for handling the risks attached to these factors. As is often the case with rules and recommendations which have been strongly influenced by lobby groups, the result turned out to have little bite in this case.

The weak response from the implementation of this standard in terms of improved transparency is explained by the fact that a quantitative analysis of the effects was not explicitly required. A study of the global automotive and paper industries shows that the "recommendations" in most cases merely resulted in explanations of the sweeping type: "unfavourable" development of important exchange rates has had a negative impact on performance (Oxelheim, 2003). At best there was an ad hoc mention of one or two macroeconomic variables. As far as the magnitude of the impact on the performance was concerned - in those few cases where variables were actually mentioned - no figures were generally provided, only that the effect would be large, small or negligible. To merely mention the variables as various categories and then speak of large or small effects can be seen as no more than an "excuse" for a poor result, and of no information-value for a shareholder interested in the prospects of the firm. In summary, none of the 62 companies in the study provided information which would enable an outside shareholder to draw a conclusion as to the "sustainability" of the performance - i.e. to the performance after the impact of macroeconomic fluctuations has been filtered out.

\subsection{The Potential Impact of IFRS/IAS 1}

IAS 1 as formulated in IFRS and implemented in 2005 within the EU contains basically the same "recommendations" as above but slightly watered down. Companies are no longer explicitly encouraged to provide information; instead Paragraph 9 (comparable with Paragraph 8 of IAS 1997 rev.) merely suggests a practice by mentioning that many companies provide information as above. On the other hand, Paragraph 116 in another section of IAS 1 sets clear requirements for information relevant to the area we are discussing. The company therefore must give details of its most important assumptions for the future and other important assessments of factors of uncertainty which may be of significance for assets and 
liabilities in coming years. Paragraphs 117-124 provide more detailed guidance but also give possibilities for exceptions. Paragraph 120 could be seen as the most important addition. This specifies that the information referred to in Paragraph 116 must be provided in a manner which assists the reader of financial statements in understanding management's assessment of the future and its view of various sources of uncertainty in the economy as well as its evaluation of the impact. Expectations of improved information provision are, however, somewhat deflated in Paragraph 121, which maintains that it is not necessary to provide budget information or forecasts as part of the requirements set in Paragraph 116. The weakness remains that there is no explicit requirement for quantitative assessment of the effects.

\subsection{Will the Supply of Information Match the Demand under IFRS?}

What does optimal transparency look like from an outside shareholder's viewpoint? For this shareholder, it is important to obtain a grasp of the intrinsic or sustainable performance, i.e. the performance which remains after the impact of macroeconomic fluctuations is filtered out. To achieve this, a "tough" version of the original IAS 1 formulation mentioned previously is required and, accordingly, a clear identification of which macroeconomic variables are most important. An outside interested party can only usefully obtain this information by means of his or her own fundamental analysis of the company's operations. In most cases there are links between different parts of the firm which reduce the possibility of an outside shareholder to effectively carry out this analysis without support from the company.

After the most important variables are presented, the shareholder then requires coefficients, describing what impact an unexpected change to the respective variable would have on the performance. To meet this demand, the company must have carried out an analysis which makes the coefficients available in a format where they are free of effects linked to the other macroeconomic variables identified. Based on this knowledge, the outside shareholder can then also form an opinion about the magnitude of the risk exposure of the firm. Finally, the shareholder wants information on what risk policy the company practices and intends to practice.

The question is whether IFRS and IAS 1 in the current form can lead to optimal transparency with regard to the significance of macroeconomic variables for the development of individual companies' "sustainable" profit and intrinsic competitiveness. Will companies regard it as optimal to satisfy the outside shareholder's need for information? There are doubtless sectors in which it may be a touchy point to provide complete information on vulnerability to changes in the macroeconomic environment. This could, for example, apply to companies with standard products and world market prices, i.e. companies which have very limited possibilities of compensating for unexpected macroeconomic fluctuations by changing their product prices.

In addition to individual companies' decisions, there is also the legislator's dilemma that many interest groups must approve legislation and recommendations in one manner or another. The bar will therefore likely be set at a level that is optimal for the majority of companies. In addition to this "soft" interpretation of the power controlling legislation and its origin, there is also a more conspiratorial one, pointing 
out the principal-agent problem, where politicians, as agents, have interests at stake in retaining power in order to gain personal advantage for themselves by so doing (Fisman, 2001). This strand of literature points out how a government may have interests at stake in maintaining a weak accounting culture. Apart from the lastmentioned interpretation - which must be seen as less likely in the EU context other considerations have probably resulted in making IFRS a collection of standards that do not reflect optimal transparency from the shareholder's perspective. It would be a marked improvement if Paragraph 9 of IAS 1 took the form of a recommendation containing quantitative provisions, supplemented by a similar clarification of Paragraph 116.

\section{MUST-Analysis and Shareholders' Information Needs}

The information in demand by shareholders should be included in the management's own decision-support in the form of the outcome of a Macroeconomic Uncertainty Strategy (MUST)-analysis (Oxelheim \& Wihlborg, 2005, 2008). The MUST analysis provides exactly the information needed by shareholders to be able to form their own assessment as to where the company is headed in terms of performance, what value the company has, what company management has actually achieved and whether this performance should be rewarded with a bonus or not.

\subsection{MUST-Analysis and Availability of Information}

The MUST-analysis starts with a fundamental analysis by which - for the individual firm - relevant macroeconomic variables are identified as a response to a set of questions such as:

1) Where does the company produce?

2) Where does it purchase its inputs from?

3) On what markets does the company sell its goods and services?

4) Which are the company's most important competitors?

5) Where do these competitors produce?

6) Where do they purchase their inputs from?

7) On what markets do these competitors sell?

8) In what currencies are the company's liabilities and financial investments?

Applying a comparable set of questions to the competitors is an important part of the fundamental analysis. Far too many companies carry out an analysis involving only listing the currencies appearing in their own accounts, and ignoring the indirect effects of macroeconomic variables through their competitors. Another important dimension of the analysis concerns the impact on demand that results from interest rate fluctuations; the latter should not only be considered as they affect borrowing cost or return on financial investments. Most companies have a clear commercial interest rate exposure without paying any attention to it!

Once all the variables that exert a potential influence on the corporate performance have been identified, the next step in the process is to examine them in order to find 
out which variables have the greatest impact. A vital part of the MUST-analysis is to identify the most important variables within the framework of a multivariate technique taking into consideration the fact that exchange rate changes, interest rate changes and price changes (inflation) are interrelated through a number of equilibrium relationships. Applying a multiple regression analysis enables us to obtain sensitivity coefficients for the partial impact on the performance. These coefficients will tell us the impact of an unexpected one percent change - in each one of the variables identified - on the performance, i.e. the impact net of the effect of other variables identified.

With the help of this procedure, management can "filter out" temporary influences from the macroeconomic environment. What remains after the filtering is the measure that should be used in the company's decision-making process (and which comprises an important part of the shareholders' information needs).

A MUST-analysis also helps identify the company's exposure to macroeconomic risks, by pointing out the magnitude of the macroeconomic influences and thereby the uncertainty concerning their future impact. This can spotlight the need for a risk management strategy. Traditional exposure coefficients are static and limited and can be directly misleading in the decision-making process. A MUST-analysis therefore contributes to improved risk awareness by making available a collection of exposure coefficients (those mentioned above) which in a simple way can be converted to hedging contracts on financial markets. Reporting these coefficients helps the shareholder, not only in filtering reported results and in undertaking scenario analysis, but also in understanding the company's risk exposure.

\subsection{Optimal Transparency for Shareholders - an Example}

External reporting that delivers the outcome of a MUST-analysis fulfils the demand for optimal transparency from the shareholders' perspective. It is also equivalent to a quantification of the contents of Paragraph 9 of IAS 1. The following is a simple example showing in concrete terms what this part of the external reporting should include. The example contains a forecast for performance over the next period, but is equally illustrative for a situation without a forecast.

Let us take an Icelandic company as an example. The fundamental analysis, described briefly above, has resulted in a limited number of macroeconomic variables that could potentially impact the company's performance. The quantitative analysis has enabled us to select the three most important variables, which turned out to be: the ISK/SEK exchange rate, short-term interest rate in Iceland, and producer prices in the US. A depreciation of the Icelandic Krona versus the Swedish Krona (SEK) will have a positive impact on the Icelandic company's performance, just as an interest rate increase will reduce the performance. Higher product prices in the US will have a positive impact on the performance of the company.

The quantitative analysis has also provided us with sensitivity/vulnerability coefficients for each of these three individual variables. The coefficients measure the change in "performance" resulting from a one percentage point unexpected change in the respective macroeconomic variable. The magnitude of the coefficients is shown in the third column of Table 1. 
Table 1. Example of optimal transparency with regard to the macroeconomic impact on performance.

Forecast: The performance will increase next quarter by 13 percent compared to the preceding quarter. The seasonal effects represent 3 percentage points of that increase. The company's policy is not to work with hedging operations of any kind on external financial markets.

\begin{tabular}{l|l|l}
\hline Variables identified & $\begin{array}{l}\text { Forecast is } \\
\text { based on the } \\
\text { following } \\
\text { assumptions }\end{array}$ & $\begin{array}{l}\text { Sensitivity coefficient: One percentage } \\
\text { point increase as compared to the } \\
\text { anticipated change will impact the } \\
\text { performance by }\end{array}$ \\
\hline $\begin{array}{l}\text { SSK/SEK } \\
\text { Phort-term rate in Iceland }\end{array}$ & $\begin{aligned} 1 \% \\
1 \%\end{aligned}$ & $2 \%$ \\
\hline
\end{tabular}

Since we provide a forecast in this example, we need to include the assumptions used in this forecast (Column 2) as input within the framework of optimal transparency. Given the information in the table, the shareholders themselves can calculate the impact on the result of a different scenario than the one presented by management. Something may have happened that makes the management scenario obsolete and the shareholders will therefore develop a new one.

A breakdown of the management scenario is as follows: the macroeconomic impact is expected to be $[2 \times 2+1 \times(-3)+1 \times 3] \%=4 \%$. The growth assumptions inherent in the forecast are therefore $[13-4-3] \%=6 \%$.

Equipped with the transparency provided by the table, shareholders can now calculate the impact of their own scenario. Our shareholder will therefore know the outcome in a scenario where the ISK depreciates by 4 percentage points against the SEK (compared with management assumption of a 2 percentage points' depreciation), the short-term rate in Iceland decreases one percentage point (compared to a 1 percentage increase) and product prices in the US rise by 2 percentage points (compared with management's assumption about only 1 percent increase). With the help of the sensitivity coefficients in the third column of the table we can calculate the impact on the outcome under the new macroeconomic assumptions. The expected performance in this new scenario would be an increase of $[4 \times 2+(-1) \times(-3)+2 \times 3+6+3]=26 \%$ over the previous period.

Let us now assume that the actual increase in performance was 16\% when macroeconomic developments proved to be exactly as assumed by the shareholder. When compared to the forecast $13 \%$, and without a further analysis, those extra 3 percentage points of growth would very likely be interpreted as an indication of improved competitiveness. Further analysis of the outcome, based on the actual development of the relevant macroeconomic variables, indicates that growth should have been $26 \%$ - since the shareholder's macroeconomic forecast proved correct according to the calculation above. Hence, the conclusion is that the company has not 
only missed its growth target, it has in fact experienced negative growth. Its intrinsic performance and competitiveness has dropped.

The management should therefore not be allowed to enjoy the fruits of an unexpected improvement in performance - an improvement which without closer examination could provide the justification for higher bonuses, wage increases and higher dividends - but should be required to provide an explanation. There could be a simple explanation, for example, that some competitor carried out a strong marketing campaign during the period concerned. If no acceptable explanation is provided, management should be required to provide an idea as to how it plans to deal with this signal of lower competitiveness and intends to regain the competitiveness lost, for example, by increasing support for product innovations as well as innovations in the production process. Clearly, transparency of this sort gives outside interested parties a better possibility for analysis and better possibilities to form opinions on how the company is managed. The increased transparency therefore prepares the way for an improved dialogue between the principal and the agent - shareholders and management - which should result in lower agency cost and risk premium.

\section{Conclusions Concerning Transparency and Economic Growth}

Many shareholders (or their analysts in particular) are no doubt tempted to try to perform a MUST-analysis of their own. But it is difficult for them to carry this out without the assistance of the company and they have to depend upon the company providing information such as that in Table 1, or assisting them with the information they require to be able to carry out the analysis. Despite the introduction of IFRS at the beginning of 2005, there is no indication in 2007 of increased transparency concerning macroeconomic impact. In the best case, financial statements include a sensitivity coefficient or two. In most cases, the impact of exchange rate changes is reported as a lump sum, based on the assumption of unchanged exchange rates. The impact of interest rate changes on business operations is simply not mentioned.

The reason that the situation today still seems so far from optimal transparency seen from the point of view of an outside shareholder - can be that the significance of the question has not been given the priority by the board that it deserves, and that management simply does not have more sophisticated information to report than what we currently see in financial statements. Another explanation could be that optimal transparency from the company's perspective means not disclosing too much of its vulnerability for its competitors, a position which by extension can be justified as consistent with optimal transparency from the shareholders' perspective. In such case the latter must depend upon the management without having a better understanding of developments.

There are numerous indications, however, that information disclosure is moving closer to what is needed and in demand by shareholders in accordance with Table 1 above. These indications include, apart from the speed of development of information technology itself: a) the implementation of IFRS and similar efforts; $b$ ) increased financial analyst competence; c) the availability of the MUST-analysis and similar analytical approaches; d) an increased interest in Value Based Management 
(VBM), which emphasizes the need to separate the value created by temporary factors from the "sustainable" value; e) an increased demand within banks and financial institutions for more information for risk assessment in line with Basel 2; f) an increased focus on environmental scanning requiring information which is suitable for scenario analysis; g) increased cross-border M\&As in an integrated world with higher demands for information on the sensitivity to macroeconomic fluctuations; h) a greater focus on information on vulnerability to macroeconomic fluctuations for listing on international securities exchanges; plus i) the new rules against selective information disclosure adopted by the Securities and Exchange Commission in October 2000, which increase the significance of presenting in a comprehensive format the impact of macroeconomic fluctuations through traditional accounting channels such as the annual report.

It is important for outside interested parties, whether shareholders, analysts or creditors, to understand the company's sustainable performance and thereby its competitiveness and capacity to survive. At the national level, increased transparency should be a leading concern for a country's politicians, since a more precise definition of information provision in the direction of what we have identified as optimal transparency can be expected to lead to lower agency costs and risk premia, lower cost of capital, higher investment and higher economic growth. Without the addition of an explicit requirement for information in quantified form, in accordance with the principles discussed above, IFRS as implemented in the EU from 2005 will neither result in increased transparency nor, in turn, in higher economic growth.

\section{References}

Bushman, R. M., Piotroski, J. D. \& Smith, A. J. (2004). What Determines Corporate Transparency, Journal of Accounting Research 42:2, pp. 207-252.

Fisman, R. (2001). Estimating the Value of Political Connections, American Economic Review 91, pp. 1095-1102.

Forssbaeck, J. \& Oxelheim, L. (2006). Transparency, Capital Formation and Economic Growth. In L. Oxelheim (Ed.), Corporate and Institutional Transparency for Economic Growth in Europe. Elsevier, Oxford.

Gustavsson, S., Oxelheim, L. \& Wahl, N. (eds.) (2005). Lissabonstrategin i halvtid. Santérus Förlag, Uppsala.

Jensen, M. C. \& Murphy, K. J. (1990). Performance Pay and Top-Management Incentives, Journal of Political Economy 98, pp. 225-264.

Levine, R. (1997). Financial Development and Economic Growth: Views and Agenda, Journal of Economic Literature 35, pp. 688-726.

Morris, S. and Shin, H.S. (2002). Social Value of Public Information, American Economic Review 92:5, pp. 1521-1534.

Oxelheim, L. (1996). Financial Markets in Transition - Globalization, Investments and Economic Growth, Routledge and Thomson International Press, London. 
Oxelheim, L. (2001). Routes to Equity Market Integration/the Interplay between Politicians, Investors and Managers, Journal of Multinational Financial Management 11, pp. 183-211.

Oxelheim, L. (2003). Macroeconomic Variables and Corporate Performance, Financial Analysts Journal 59:4, pp. 36-50.

Oxelheim, L. (red) (2006). Corporate and Institutional Transparency for Economic Growth in Europe. Elsevier, Oxford.

Oxelheim, L. \& Ghauri, P. (2004). The Race for FDI in the European Union. In L. Oxelheim \& P. Ghauri (Eds.) European Union and the Race for Foreign Direct Investment in Europe. Elsevier, Oxford

Oxelheim, L. \& Randöy, T. (2003). The Impact of Foreign Board Membership on Firm Value, Journal of Banking and Finance 27, pp. 2369-2392.

Oxelheim, L. \& Randöy, T. (2005). The Anglo-American Financial Influence on CEO Compensation in Non-Anglo American Firms, Journal of International Business Studies 36:4, pp. 470-483.

Oxelheim, L. \& Wihlborg, C. (2003). Recognizing Macroeconomic Fluctuations in Value Based Management, Journal of Applied Corporate Finance 15:4, pp. 104-110.

Oxelheim, L. \& Wihlborg, C. (2005). Corporate Performance and the Exposure to Macroeconomic Fluctuations. Norstedt Academic Publishers, Stockholm.

Oxelheim, L. \& Wihlborg, C. (2008). Corporate Decision-making with Macroeconomic Uncertainty, Oxford University Press, New York (forthcoming).

Reese, M., \& Weisbach, M. (2002). Protection of Minority Shareholder Interests, Cross-Listings in the United States, and Subsequent Equity Offerings, Journal of Financial Economics 66, pp. 65-104.

Verrecchia, R. (2001) Essays on Disclosure, Journal of Accounting and Economics 31/32, pp. 97-180. 